\title{
BMJ Global Health Mortality estimates for WHO SEAR countries: problems and prospects
}

\author{
Chalapati Rao (1) , ${ }^{1}$ Kanitta Bundhamcharoen, ${ }^{2}$ Matthew Kelly (1) , \\ Viroj Tangcharoensathien ${ }^{2}$
}

To cite: Rao C,

Bundhamcharoen $\mathrm{K}$, Kelly M, et al. Mortality estimates for WHO SEAR countries: problems and prospects. BMJ Global Health 2021;6:e007177. doi:10.1136/ bmjgh-2021-007177

Handling editor Seye Abimbola

Received 13 August 2021 Accepted 30 September 2021

Check for updates

(C) Author(s) (or their employer(s)) 2021. Re-use permitted under CC BY-NC. No commercial re-use. See rights and permissions. Published by BMJ.

${ }^{1}$ Research School of Population Health, Australian National University, Canberra, Australian Capital Territory, Australia

${ }^{2}$ International Health Policy Program, Ministry of Public Health, Nonthaburi, Thailand

Correspondence to

Dr Chalapati Rao

chalapati.rao@anu.edu.au

\section{ABSTRACT}

Cause-specific mortality estimates for 11 countries located in the WHO's South East Asia Region (WHO SEAR) are generated periodically by the Global Burden of Disease (GBD) and the WHO Global Health Estimates (GHE) analyses. A comparison of GBD and GHE estimates for 2019 for 11 specific causes of epidemiological importance to South East Asia was undertaken. An index of relative difference $(\mathrm{RD})$ between the estimated numbers of deaths by sex for each cause from the two sources for each country was calculated, and categorised as marginal $(\mathrm{RD}= \pm 0 \%-9 \%)$, moderate $(\mathrm{RD}= \pm 10 \%-19 \%)$, high $(\mathrm{RD}= \pm 20 \%-39 \%)$ and extreme $(\mathrm{RD}> \pm 40 \%)$. The comparison identified that the RD was $>10 \%$ in two-thirds of all instances. The RD was 'high' or 'extreme' for deaths from tuberculosis, diarrhoea, road injuries and suicide for most SEAR countries, and for deaths from most of the 11 causes in Bangladesh, DPR Korea, Myanmar, Nepal and Sri Lanka. For all WHO SEAR countries, mortality estimates from both sources are based on statistical models developed from an international historical causespecific mortality data series that included very limited empirical data from the region. Also, there is no scientific rationale available to justify the reliability of one set of estimates over the other. The characteristics of national mortality statistics systems for each WHO SEAR country were analysed, to understand the reasons for weaknesses in empirical data. The systems analysis identified specific limitations in structure, organisation and implementation that affect data completeness, validity of causes of death and vital statistics production, which vary across countries. Therefore, customised national strategies are required to strengthen mortality statistics systems to meet immediate and long-term data needs for health policy and research, and reduce dependence on current unreliable modelled estimates.

\section{INTRODUCTION}

Timely and reliable mortality statistics by age, sex and cause are primary empirical evidence for population health development strategies; and are required to inform progress against many indicators of the United Nations Sustainable Development Goals (UNSDGs) for 2030. ${ }^{1}$ National Civil Registration and Vital Statistics (CRVS) systems are the optimal source for mortality statistics to monitor
Summary box

In the absence of empirical data, mortality indicators for WHO South East Asia Region (SEAR) countries are estimated by international agencies and research groups using statistical models.

- Comparison of mortality measures from different estimation exercises demonstrate large variations at country level for specific causes of death.

- As a result, such modelled estimates are not reliable evidence for population health assessment, health policy or research.

- An evaluation of national mortality statistics systems in WHO SEAR countries identified specific challenges related to structure and organisation, operations and technical capacity that influence data availability and quality.

- The analysis offers recommendations for a strategic approach to design and implement mortality statistics system strengthening programmes that will generate routine and reliable empirical data in SEAR countries.

progress towards the UNSDGs. ${ }^{2}$ However, inadequacies in national CRVS systems have limited the availability of reliable information on deaths by age, sex and cause for over twothirds of all countries. ${ }^{3}$ In particular, there is a critical need for good quality mortality statistics for the 11 countries located in the WHO South East Asia Region (WHO SEAR) given that the region contains more than a quarter $(26.1 \%)$ of the global population, and which is currently experiencing profound demographic and epidemiological transitions. ${ }^{4}$

The WHO SEAR countries comprise three with large populations (more than 150 million) which are India, Indonesia and Bangladesh; five with medium sized populations (20-70 million) which are Thailand, Myanmar, Nepal, DPR Korea and Sri Lanka and three with small populations $(<1$ million $)$ namely Bhutan, Maldives and Timor Leste. In addition to these variations in population size, there is considerable diversity in terms of geographical spread, environment and climate patterns, economic profile, culture 
and language across the region, which highlights the need for health actions that are based on local epidemiological evidence. However, in the absence of reliable nationally representative empirical data, current mortality estimates for these countries in the SEAR are derived from international demographic and epidemiological statistical models. ${ }^{5}$ Given the limited local data inputs, there is considerable uncertainty in these modelled estimates. ${ }^{67}$

Over the past three decades, there have been several iterations of global, regional and national population health estimations as part of the Global Burden of Disease (GBD) study framework. ${ }^{8}$ Currently, the Institute of Health Metrics and Evaluation (IHME), University of Washington is the lead institution for the annual GBD estimation series, and the estimates for 2019 were released in October 2020. ${ }^{9}$ In parallel, the WHO also conducts an alternate analysis to derive Global Health Estimates (GHE), which essentially comprise the same set of mortality and morbidity statistics for each country, as the GBD estimates. ${ }^{11}$ The WHO GHE estimates for 2019 were released in December 2020. ${ }^{12}$ This article compares the two separate GBD and GHE cause-specific mortality estimates for 11 WHO SEAR countries in 2019, along with a discussion of the variations between these estimates, and their implications. This analysis also reviews the current status of the mortality statistics systems in these countries, and proposes a strategic approach to strengthen the availability of routine and reliable empirical data on mortality and causes of death on a timely basis.

\section{REVIEW OF CURRENT MORTALITY ESTIMATES}

A general description of the approaches employed by the WHO GHE and IHME GBD study teams for mortality estimation helps place the comparative analysis into context. As part of its annual appraisal of the global, regional and national landscape of population health status and trends, the WHO publishes an annual statistics report which includes detailed estimates of deaths by age, sex and cause of death for each country. ${ }^{13}$ To develop these estimates, all Member States are required to submit annual reports of primary mortality statistics to the WHO, which are then used as the basis for the annual World Health Statistics Report. However, only 70 of the 194 countries in the world submit annual CRVS data on cause-specific mortality of adequate quality for WHO direct use in global mortality assessments. ${ }^{14}$ The WHO GHE data analysis team applies several data corrections and adjustments based on international epidemiological models to derive mortality estimates by age, sex and cause for these 70 countries. ${ }^{11}$ Several other countries submit data which are either incomplete or with poor cause attribution, owing to limitations in national mortality statistics systems. Hence, for these countries with partial data which is not of good quality, and all other countries without national data, the WHO GHE employs a modelling approach to derive mortality estimates, as discussed later.

The IHME GBD study also implements an annual activity to develop cause-specific mortality estimates for all countries. In brief, estimation for each country is based on a two-step process, the first being an estimation of the total national deaths by age and sex. This is achieved by modelling age-specific death rates (ASDRs) by sex for each WHO SEAR country, and then applying these ASDRs to respective national age-sex population estimates developed by the IHME GBD team, to derive the national age-sex estimates of deaths from all causes. In the second step, a modelled cause of death distribution is fitted to the estimated total numbers of deaths in each age-sex category, to derive the complete set of national mortality estimates by age, sex and cause. The GBD modelled national cause of death distributions are derived from a historical international database of mortality data from all countries, with specific criteria applied when considering each country-year of data for inclusion in the database. For each country, the GBD models use national data on a range of covariates associated with mortality as inputs, along with input values on cause of death distributions from the international mortality database. The choice of cause of death input values in the modelling process varies for each country, according to the quality of national data included in the GBD historical mortality database. For countries with good quality national data, the GBD modelled cause of death distributions are only based on national covariates and the cause of death data from all countries assigned good quality data scores. For each of the remaining countries, the GBD modelled distributions are based on national covariates and the entire international mortality database. Further details on the GBD estimation methodology are available elsewhere. ${ }^{515}$ As a result, the GBD generates estimates of deaths by age, sex and cause for all countries.

To complete its estimation for the remaining countries without good quality national data, (which includes the 11 SEAR countries) the WHO GHE methods use these GBD national estimates as a starting point. First, the GHE analysis takes the GBD modelled ASDRs by sex for each country and applies them to the United Nations Statistics Division (UNSD) age-sex population estimates developed under the World Population Prospects 2019 revision, ${ }^{16}$ to derive the GHE estimate of total deaths by sex and age for each country. Then, the GHE process adjusts the GBD estimated cause of death distribution patterns using evidence from several international disease-specific epidemiological models developed by the WHO, to derive the national GHE estimated cause of death distributions. In the final step, these GHE cause of death distributions are

\footnotetext{
'The IHME mortality database assigns a score of 'well-certified' deaths, in a national dataset according to the completeness of recorded deaths and specificity of assigned causes of death. A score of $\geq 85 \%=\operatorname{good}$ quality.
} 
applied to the GHE estimates of total deaths, to derive the final GHE estimates of cause-specific mortality.

In summary, these processes result in two separate sets of mortality estimates by age, sex and cause for each country. The most recent estimates from GBD 2019 were released in October 2020; and the GHE estimates were subsequently released in December 2020, ${ }^{10} 12$ and their respective publicly available databases were accessed to extract the required mortality estimates for comparison. ${ }^{9} 1017$

\section{COMPARISON OF ESTIMATES}

For each WHO SEAR country, GBD and GHE estimates of total deaths in 2019 from 11 causes of death of epidemiological significance in South East Asia were extracted. These causes included a selection of common infectious diseases, neonatal conditions, major non-communicable diseases and selected forms of injury. For each cause, the variations between GBD and GHE estimates were analysed by computing the relative difference (RD) between the estimates from each source at national level, as follows:

$\%$ relative difference $(\mathrm{RD})=\frac{\text { GBD estimate }- \text { GHE estimate }}{\text { GHE estimate }} \times 100$

Estimates for total deaths for each sex from each cause were used as the base numbers for calculating the RD. We propose four levels of $\mathrm{RD}$ as follows:

a. Marginal: $\mathrm{RD}= \pm 0 \%$ to $9 \%$.

b. Moderate: $\mathrm{RD}= \pm 10 \%$ to $19 \%$

c. High: $\mathrm{RD}= \pm 20 \%$ to $39 \%$.

d. Extreme: $\mathrm{RD}> \pm 40 \%$.

A broad comparative assessment of the results for the 11 Member States of WHO SEAR is presented in table 1. Out of a total of 242 instances presented in table 1, about one-third had marginal RD $( \pm 10 \%)$, about half had moderate to high RD (11\%-40\%) and $17 \%$ had extreme $\mathrm{RD}(> \pm 40 \%)$.

Specifically, the RD is above $20 \%$ in almost all countries for tuberculosis, diarrhoeal diseases, road injuries and suicide. For India and Indonesia, although the RD is of lesser degree for most causes, these translate into considerable differences in terms of number of deaths, due to their larger populations. On the other hand, the magnitude of RDs for most of the 11 causes of interest in Bangladesh, DPR Korea, Myanmar, Nepal and Sri Lanka are a cause for policy concern, in the absence of any explanation for one estimate being more accurate than the other. Variations in ranks for these causes from each source (online supplemental appendix 1) also limit the use of these mortality estimates for health sector priority setting. It must be borne in mind that even where both estimates are similar, there is potential for both being equally incorrect, due to the absence of any reliable empirical local data inputs for the verification of the modelling outcomes. ${ }^{5}$ Under these circumstances, these differences between the estimates, without any rational basis to evaluate the veracity of one estimate as compared with the other, renders neither estimate to be reliable evidence for monitoring population health status and evaluation of health policy and interventions.

These findings underscore the urgent need for reliable local data for cause-specific mortality statistics in SEAR countries, or at least to serve as viable inputs into an estimation process that clearly tracks the adjustments to local data, in deriving final population level estimates. An analysis of gaps in current CRVS system design and/ or implementation in SEAR countries is presented in the following sections. The findings and recommendations from this gap analysis serve as essential starting points for a strategic approach to system strengthening activities, with a goal to establish a robust CRVS system which registers all deaths and generates accurate cause-specific mortality statistics on a timely basis.

\section{REVIEW OF NATIONAL MORTALITY STATISTICS SYSTEMS}

Unavailability of reliable mortality statistics for SEAR countries has been a protracted challenge for several decades. ${ }^{18-20}$ To address this situation, the WHO SEAR Office has conducted several developmental activities over the past 15 years, starting with a Regional Consultation on this subject in $2007 .{ }^{21}$ Subsequently, a series of national level CRVS assessments were conducted during 2011-2013, the findings from which were used to inform development of a regional strategic plan to strengthen CRVS systems over the decade of 2015-2024. ${ }^{22}$ The WHO SEARO strategic plan was aligned with the United Nations Economic and Social Commission for Asia Pacific (UNESCAP) Regional Action Framework under their CRVS Decade 2015-2024 initiative. ${ }^{23}$ As part of the CRVS Decade programme, all countries undertook initiatives to strengthen CRVS systems, either with international technical and funding support or through national programmes focusing on birth and death registration. However, a mid-term review of the UNESCAP initiative in 2019-2020 found that only three countries (India, Sri Lanka and Thailand) had reported over 90\% completeness of death registration, as estimated by their national statistical agencies. Moreover, the ascertainment of causes of death was a persistent problem for all WHO SEAR countries. ${ }^{24}$ For India, it should be noted at subnational levels, that there were several states with relatively lower levels of reported completeness of death registration, indicating the need for a continued effort to record all deaths. ${ }^{25}$

In recognition of these persistent critical gaps in mortality data availability, the WHO SEAR Office commissioned a regional situational assessment of CRVS systems in 2019-2020, with a focus on mortality statistics. ${ }^{26}$ For each country, national CRVS laws and regulations, field operating procedures, vital event registration forms, data management tools and processes, and statistical reports were reviewed according to a framework for CRVS 


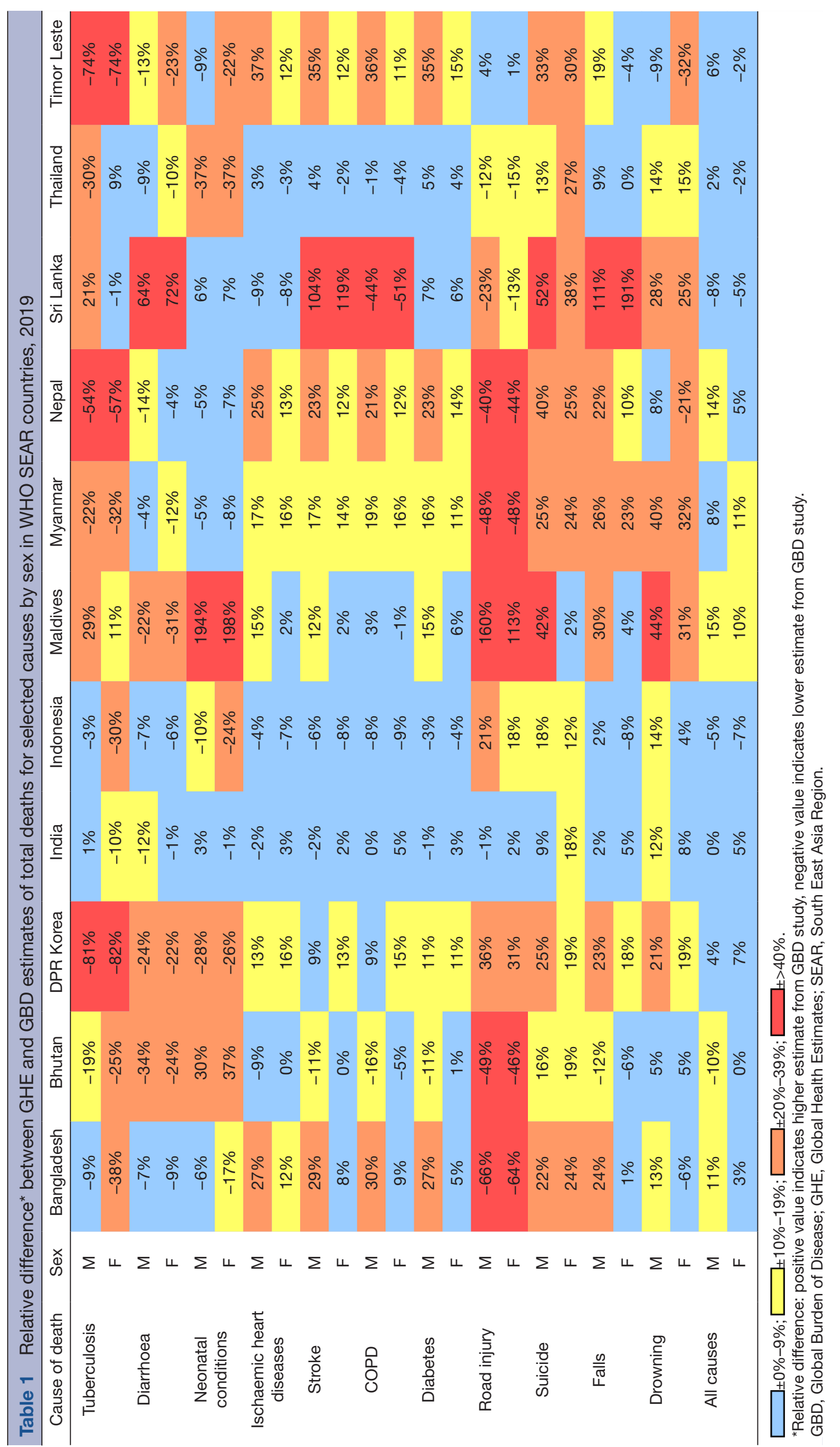


evaluation developed by the United Nations Statistics Division (UNSD). ${ }^{27}$ Broadly, the UNSD CRVS evaluation framework examines the legal basis and institutional procedures for CRVS, the operational characteristics of implementation, the availability of resources and the vital statistics practices. The review covered eight countries of the region, excluding DPR Korea, Thailand and Sri Lanka. For Sri Lanka and Thailand, similar information was obtained through direct contact with national researchers. This manuscript reports the salient aspects of the organisation, design and operations of national systems that are relevant to the compilation of mortality statistics.

\section{DESIGN CHARACTERISTICS OF CRVS SYSTEMS}

Table 2 describes the major features of current CRVS systems in the 11 countries under consideration. Eight countries have specific laws pertaining to CRVS. For Bhutan, the requirement for birth registration is stated under the Citizenship Act of 1977, while for death registration, a form with necessary instructions is documented in the Census Handbook of 1993. For Myanmar, there are nine separate laws that mention various provisions for registration of births and deaths, the most recent being the Ward and Village Tract Administration Law of 2012. ${ }^{28}$ In Timor Leste, vital registration is conducted according to a regulation $(3 / 2001)$ formulated by the United Nations Transitional Administration in East Timor. For India, the legal framework facilitates decentralised implementation with each state enacting its specific operational rules and regulations, while the central government issues periodic updates to the general principles for civil registration, along with revisions to processes for compilation and reporting of vital statistics. The most recent vital statistics updates included a general instruction in 2014 that mandated the coverage of all health facilities under the Medical Certification of Cause of Death (MCCD) scheme, and a circular in 2017 instructing all districts to compile, monitor and report vital statistics on births and deaths on a monthly basis. ${ }^{29} 30$ Similarly, in 2019, the government of Indonesia has published a Regulation on the National Strategy for the Acceleration of Population Administration for the Development of Vital Statistics, which includes instructions and targets for CRVS development. ${ }^{31}$ Several other countries (Bangladesh, Sri Lanka and Nepal) are also undertaking updates to their CRVS legal and administrative mechanisms, all of which indicate a renewed and positive focus towards strengthening CRVS systems in the region.

For implementation, all WHO SEAR countries have established extensive networks of registration centres in urban and rural areas. As the largest country in the region, India operates over 280000 centres, with a high reporting coverage and completeness of birth and death registration. ${ }^{25}$ In Indonesia, the government has instituted a process for decentralising the functions of registration from the existing offices in districts and cities to all the 7246 subdistricts in its 34 provinces. This will ensure direct accessibility of registration services, especially to the rural citizens residing in over 75000 villages across the country. ${ }^{31}$ Similarly, Nepal, given its challenging geographical terrain, has established registration centres in all its villages and urban wards through expanding online registration. Bangladesh and Bhutan have established infrastructure throughout the country for online birth and death registration services. ${ }^{26}$ Sri Lanka, Maldives and Thailand have already achieved total national coverage and completeness of CRVS.

Despite these developments in administration and infrastructure for CRVS systems, there are several constraints from the perspectives of system design, operational procedures, and institutional/human capacity that hinder efficient implementation. For instance, only three countries have death reporting periods of less than a week. Such periods should be reduced for the other countries, since it is readily understood that longer durations can increase the likelihood for events to remain unregistered. From an operational perspective, nearly all SEAR countries legally mandate the WHO International Form for MCCD for events that occur in all health facilities within the country. ${ }^{32}$ Although, routine implementation is practiced only in Maldives, Sri Lanka and Thailand. As mentioned previously, MCCD coverage is currently being expanded in India. In Bangladesh, Indonesia and Nepal, initiatives have been launched to officially introduce the MCCD form in some health facilities. ${ }^{26}$ The SEA regional CRVS review noted that there was a widespread need to strengthen operational procedures for cause of death ascertainment for both institutional and domiciliary events in all countries. On a more positive note, it was observed that the reporting of stillbirths is legally or procedurally mandated in all SEAR countries except Thailand and Timor Leste. Even in Thailand, although stillbirths are not mandated under existing vital statistics practices, information on such events in health facilities is captured by the routine health information systems.

Finally, the SEA regional review evaluated the status of countries in regard to compliance with international mandates for reporting vital statistics, which are implemented under the United Nations Annual Demographic Yearbook System, and the WHO Mortality Database System. ${ }^{11} 33$ It was found that during the period from 2015 to 2018, only Maldives and Thailand had reported mortality statistics to both systems, and none of the remaining SEAR countries were fully compliant with such international reporting mandates. In regard to data quality, the WHO Mortality Database System assigns scores to data from countries that take into account data completeness, timeliness and quality of registered causes of death, and assigned 'low quality' scores to both Maldives and Thailand..$^{11}$ Although Sri Lanka also reports data on causes of death to the WHO, such data has not been submitted since 2014 . 


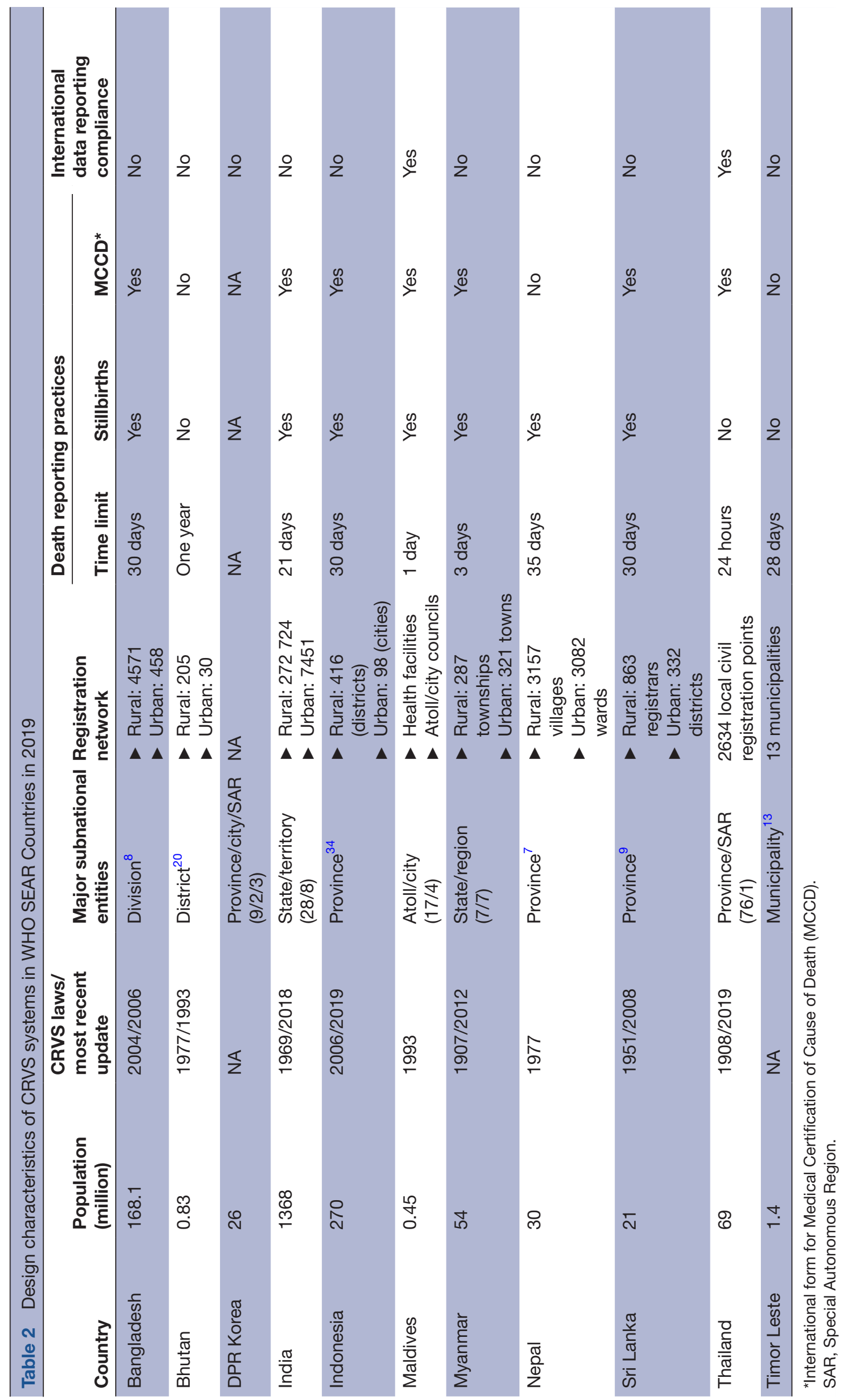

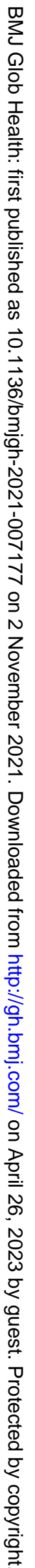


Table 3 Current availability of mortality and cause of death statistics for WHO South East Asia Region countries, 2017-2019

\begin{tabular}{|c|c|c|c|c|c|c|c|}
\hline Country & $\begin{array}{l}\text { Data } \\
\text { year }\end{array}$ & Data source & $\begin{array}{l}\text { Reported } \\
\text { CRVS deaths }\end{array}$ & $\begin{array}{l}\text { National estimate } \\
\text { of completeness } \\
\text { (\%) }\end{array}$ & $\begin{array}{l}\text { Reported } \\
\text { deaths with } \\
\text { MCCD (\%) }\end{array}$ & $\begin{array}{l}\text { MCCD with } \\
\text { ill-defined } \\
\text { causes }^{*}(\%)\end{array}$ & $\begin{array}{l}\text { CRVS } \\
\text { committee } \\
\text { established }\end{array}$ \\
\hline Bangladesh & 2018 & $\begin{array}{l}\text { UNESCAP } \\
\text { questionnaire } \dagger\end{array}$ & 196910 & 24 & 12.5 & 3 & 2017 \\
\hline Bhutan & 2018 & $\begin{array}{l}\text { UNESCAP } \\
\text { questionnaire }\end{array}$ & 3914 & 74 & Nil & Not applicable & No \\
\hline DPR Korea & NA $\ddagger$ & NA & NA & NA & NA & NA & NA \\
\hline India & 2019 & $\begin{array}{l}\text { Vital Statistics } \\
\text { Report } 2019^{25}\end{array}$ & 7641076 & 92 & 21 & 13 & 2012 \\
\hline Indonesia & 2018 & $\begin{array}{l}\text { UNESCAP } \\
\text { questionnaire }\end{array}$ & $407518 \S$ & 25 & 50 & 35 & 2019 \\
\hline Maldives & 2019 & $\begin{array}{l}\text { Maldives Health } \\
\text { Profile } 2019^{37}\end{array}$ & 1054 & 100 & 100 & 28 & 2017 \\
\hline Myanmar & 2017 & $\begin{array}{l}\text { Statistical } \\
\text { Yearbook } 2019^{36}\end{array}$ & 231210 & 59 & 19 & NA & 2014 \\
\hline Nepal & 2017 & $\begin{array}{l}\text { UNESCAP } \\
\text { questionnaire }\end{array}$ & $\begin{array}{l}\text { Not } \\
\text { specifiedף }\end{array}$ & 54 & Nil & Not applicable & No \\
\hline Sri Lanka & 2019 & $\begin{array}{l}\text { Census and } \\
\text { Statistics } \\
\text { website }^{38}\end{array}$ & 146053 & 98 & NA & NA & 2019 \\
\hline Thailand & 2018 & $\begin{array}{l}\text { Public Health } \\
\text { Statistics } 2018^{34}\end{array}$ & 475793 & 96 & 45 & 24 & $2010 / 2021^{\star x}$ \\
\hline Timor Leste & 2018 & $\begin{array}{l}\text { UNESCAP } \\
\text { questionnaire }\end{array}$ & 2187 & 23 & Nil & Not applicable & 2017 \\
\hline
\end{tabular}

${ }^{*}$ Coded to the International Classification of Diseases and Related Health Problems 10th Revision (ICD-10) chapter for 'Symptoms, signs and ill-defined conditions'.

†Questionnaire canvassed by UNESCAP to all regional countries to report progress towards the CRVS Decade 2015-2024 targets and goals. $^{24}$

$\ddagger N A=$ data not available.

§Indonesian data are from the health sector recording system.

IThe actual numbers of deaths are not mentioned, and only the per cent of data completeness is provided in the questionnaire.

**Thailand has reconstituted the National CRVS committee in 2021.

CVRS, Civil Registration and Vital Statistics; MCCD, Medical Certification of Cause of Death; UNESCAP, United Nations Economic and Social Commission for Asia Pacific.

\section{VITAL STATISTICS DATA AVAILABLE FROM NATIONAL SOURCES}

To gain a more realistic understanding of the status of mortality data availability, the SEA regional CRVS review also examined national data sources and reports on vital statistics. Table 3 shows that five SEAR countries-India, Maldives, Myanmar, Sri Lanka and Thailand have established national practices for production and dissemination of mortality statistics from CRVS systems. Of these, only Thailand had an established practice for publishing a complete annual vital statistics report based on CRVS data. The Thai vital statistics report is comprehensive in content, including statistics on births, age-specific fertility rates, age-sex specific mortality rates, life expectancies and summary tabulations of deaths by age, sex and cause of death. ${ }^{34}$ Several key vital statistics indicators are also available for major regions and provinces of Thailand. For India, annual vital statistics reports provide data on registered births by sex, stillbirths, crude birth and death rates, and numbers of deaths by age and sex for all major subnational states and territories. ${ }^{25}$ The report also provides subnational estimates of birth and death registration completeness, as well as summary data on registered births and deaths for all 718 districts. The civil registration data reports do not publish age-specific fertility or mortality rates. A separate annual report provides data on medically certified causes of death, the most recent of which included information on underlying causes of death for 1571540 deaths (20.7\% of registered deaths) in $2019 .^{35}$

Myanmar publishes several mortality indicators in a section within the annual national statistics report. The most recent report with data for 2017 includes information on total numbers of registered deaths, ASDRs, and cause-specific death rates for leading causes of death in urban areas. ${ }^{36}$ Maldives publishes an Annual Health profile which is comprehensive in content. ${ }^{37}$ Sri Lanka publishes data on registered births, deaths and causes of death in tabular format on the Department of Census and Statistics website, but there is no accompanying descriptive or analytical text report. ${ }^{38}$ Although the 
remaining countries do not have any official processes for dissemination of vital statistics from civil registration, they have reported data on registered deaths and proportion with medically certified causes under the UNESCAP CRVS decade midterm reporting system. ${ }^{24}$ However, the reported data for Indonesia are only for deaths recorded by the health sector, and not from the CRVS system. Table 3 shows that although national capacity for mortality statistics compilation exists across the SEAR, the data are incomplete for most countries, and there is a critical gap in reliable data on causes of death for all SEAR countries. Even where MCCD is implemented, there are relatively high proportions of deaths that are assigned to ill-defined causes, up to $35 \%$ in Indonesia, and this is a key limitation in the quality of available death registration data.

From a development perspective though, it is encouraging to note that except for Bhutan, Nepal and DPR Korea, all the remaining countries have established national CRVS coordination committees, with a mandate to design and implement system strengthening activities towards improving the availability and utility of mortality statistics for monitoring progress towards the UN SDGs. For India, there are state level coordination committees that function under the guidance of the national Office of the Registrar General of India. In Bangladesh, the CRVS coordination committee has a high degree of political support from the National Cabinet Division. The recently constituted national CRVS committee in Indonesia has officially launched its CRVS acceleration strategy, while Thailand is in the process of re-establishing the national CRVS committee, with some revisions to its structure and functions. In general though, the establishment of these coordinating bodies in most countries is relatively recent, which suggests that it could take some time before their impact on the availability, completeness and quality of mortality data is seen at national level.

\section{SUMMARY OF FINDINGS}

This situational analysis of current mortality statistics for WHO SEAR countries has identified several key findings. First, major international statistical modelling exercises undertaken by the WHO GHE and IHME GBD study teams generate national mortality estimates that vary considerably for specific causes of death, with no rationale to justify the veracity of one as compared with the other. At another level, there are also separate estimates of all-cause mortality and life expectancy at birth that are generated by the United Nations World Population Prospects (see online supplemental appendix 2), which also add another layer of uncertainty to the general understanding of mortality patterns for WHO SEAR countries. ${ }^{16}$ As explained in the Methods section, there are differences in the background population exposures that are used in the GBD and GHE analytical processes to estimate all-cause mortality patterns, as well as additional adjustment procedures used by the GHE for estimating specific causes of death. These two aspects of differences in methodology are the main reasons for the differences in the estimates from the two sources. Consequently, these variations in mortality estimates from different sources as well as their limited precision (see online supplemental appendix 1) have major implications for countries attempting to use such information for assessments of disease and risk factors on national population health. For instance, Nepal has attempted to use the IHME GBD estimates for 2017 to evaluate its national burden from various forms of cardiovascular disease, but as can be seen from table 1, there are moderate to high levels of variation for mortality from stroke and ischaemic heart disease, when compared with GHE estimates. ${ }^{39}$ Similarly, India has used the GBD estimates to evaluate the impact of air pollution, although there are substantial differences in the estimated numbers of adult deaths as well as their causes which are related to exposure to air pollutants, from different sources. ${ }^{40}{ }^{41}$ The GBD estimates for Indonesia have been cited as evidence for its national road map towards universal health coverage, without taking into consideration the underlying uncertainty in these estimates for all causes of death. ${ }^{42}$ Our findings clearly demonstrate that using such unreliable evidence for policy analysis is not desirable, and there is a need for accurate empirical mortality data for all SEAR countries, which will eliminate the current reliance on such uncertain model-based mortality estimates.

The second key finding is that all WHO SEAR countries have some degree of functional death registration systems with laws, structure and organisation, which results in death recording but with varying levels of completeness and accuracy. There are certain gaps in national CRVS system design in several countries, which will need attention on a case-by-case basis. For instance, several countries need to shorten death reporting periods, which is particularly relevant to strengthen the recording of neonatal deaths. Otherwise, since both birth and death for neonatal events take place before the expiry of the currently longer reporting period, this results in neither event being reported, and hence bias in measurement of neonatal mortality rates from CRVS data. Accurate measurement of neonatal mortality is especially relevant for WHO SEAR countries, since substantial reductions in under-five mortality has compressed early age mortality to the neonatal period, which is now the focus under the UN SDG programme. Shorter death reporting periods are also important for complete and timely recording of adult deaths, for which early follow-up activities are required for accurate ascertainment of causes of death. ${ }^{43}$ In other instances, there is a need to undertake programmes for decentralisation or to increase the provision of infrastructure. An overarching requirement is the need to build institutional and human capacity for ascertainment of causes for both hospital and domiciliary deaths in all countries. Nevertheless, all countries have demonstrated commitment towards system improvement through establishment of national CRVS coordination 
and technical committees, which is a positive step towards improving system performance.

The third key finding from the review is the critical gap in the production and dissemination of vital statistics in most countries. Although the CRVS systems review indicates that there is a fair degree of death reporting and registration at the local level, the challenges in vital statistics production potentially arise from weak processes for data compilation. The in-depth country case studies conducted during the regional review identified that several countries operate separate vital event reporting systems in parallel, one through the official CRVS programme by the administrative sector, and the second through the health sector information systems. This results in incompleteness of data from either source, and can be resolved by improved local coordination, data sharing and integration mechanisms. For India, the reported completeness of $92 \%$ at national level needs to be confirmed through applying alternate estimation techniques, which would also be useful in evaluating subnational variations in completeness by location, sex and age categories, where feasible. ${ }^{44}$ At another level, there are clear gaps in the availability of data on causes of death, for which separate technical resources are needed for cause of death ascertainment, data processing and coding, and statistical analysis. The relatively high proportions of ill-defined causes for medically certified deaths in several countries as shown in table 3 calls for close attention to training physicians for this function at all levels of national health systems. ${ }^{45}$ Since a considerable proportion of deaths in all SEAR countries occur at home in the absence of medical attention, there is a need to use verbal autopsy (VA) methods for cause of death ascertainment, as recommended by the WHO. ${ }^{43}{ }^{46}$ Overall, the findings from table 3 are indicative of the critical gaps in these functions across the region. In summary, a comprehensive strategy is required to address the challenges in vital statistics compilation and production, which is customised to the specific national needs and circumstances for each WHO SEAR country.

\section{WAY FORWARD}

The challenges in dealing with variations in available estimates including those derived by expert analysis of national data have been well recognised in Thailand, emphasising the need for reliable empirical data. ${ }^{47}$ To achieve this goal, a strategy has been devised that focusses on strengthening data on causes of death, as the Thai death registration system has already achieved very high levels of completeness. Since 2020, initiatives have been launched to strengthen MCCD through quality audit protocols at hospitals, implementation research to test the feasibility of using VA methods to strengthen cause of death attribution for domiciliary deaths, and a trial in using automated programmes for selection and coding of underlying causes of death. These activities are targeted towards the reduction in the proportion of deaths that are coded to ill-defined causes (currently 24\%), and to improve efficiency and timeliness in data compilation and analysis.

In other countries too, activities over the past 5 years generally indicate a definite increase in death reporting and registration at the local level, although these have not yet translated into improvements in the overall availability of statistics. ${ }^{48}$ The findings in table 3 indicate that all countries have some established processes for data compilation, although with varying levels of completeness. For instance, Bangladesh has undertaken steps to augment the role of the health sector in death notification and implementation of VA methods, through a successful small project that is currently being scaled up to increase coverage. ${ }^{49}$ Indonesia too has launched a CRVS strengthening initiative involving health sector institutions, with pilot studies demonstrating completeness levels of over $80 \%$ in two field sites (CR, personal communication). Overall, the COVID-19 pandemic has also raised awareness in most countries about the importance of mortality data, and several countries have initiated steps to augment death recording and data compilation. ${ }^{50}$ However, careful attention is required in planning scale up of these activities.

In principle, the three main focal areas for improving data availability are the completeness of death registration, the quality of recorded causes of death, and mortality statistics production. There are specific elements of national CRVS systems that influence these three focal areas in different countries, in terms of their structure and organisation, their operational framework and the nature of technical support required for efficient system performance. Table 4 provides a sample of these elements, which could serve as a general guide for each country as to which of these would need attention, when developing mortality statistics strategic development plans according to national system characteristics. The regional review in 2020 provides recommendations on the specific elements from table 4 that should be the focus for system strengthening priority actions for each country. ${ }^{26}$ For instance, improvements in death registration completeness in Bangladesh would occur through a reduction in the reporting period as well as through improving local intersectoral coordination, while Myanmar would need to strengthen and harmonise various legal frameworks as well as undertake decentralisation protocols for implementation. With relatively high levels of death registration completeness in many states, India would need to focus attention on strengthening the methodology for cause of death ascertainment, for both hospital and domiciliary deaths. These are merely a snapshot of the likely priorities for these countries, to illustrate the parameters that would need to be considered in developing the national strategic approach.

Given the diversity among SEAR countries, national strategic approaches would need to be customised to meet the long-term requirements of universal coverage and completeness of death registration, as well as immediate 
Table 4 Selected topics to be considered in national strategic plans for mortality statistics strengthening in South East Asia Region countries

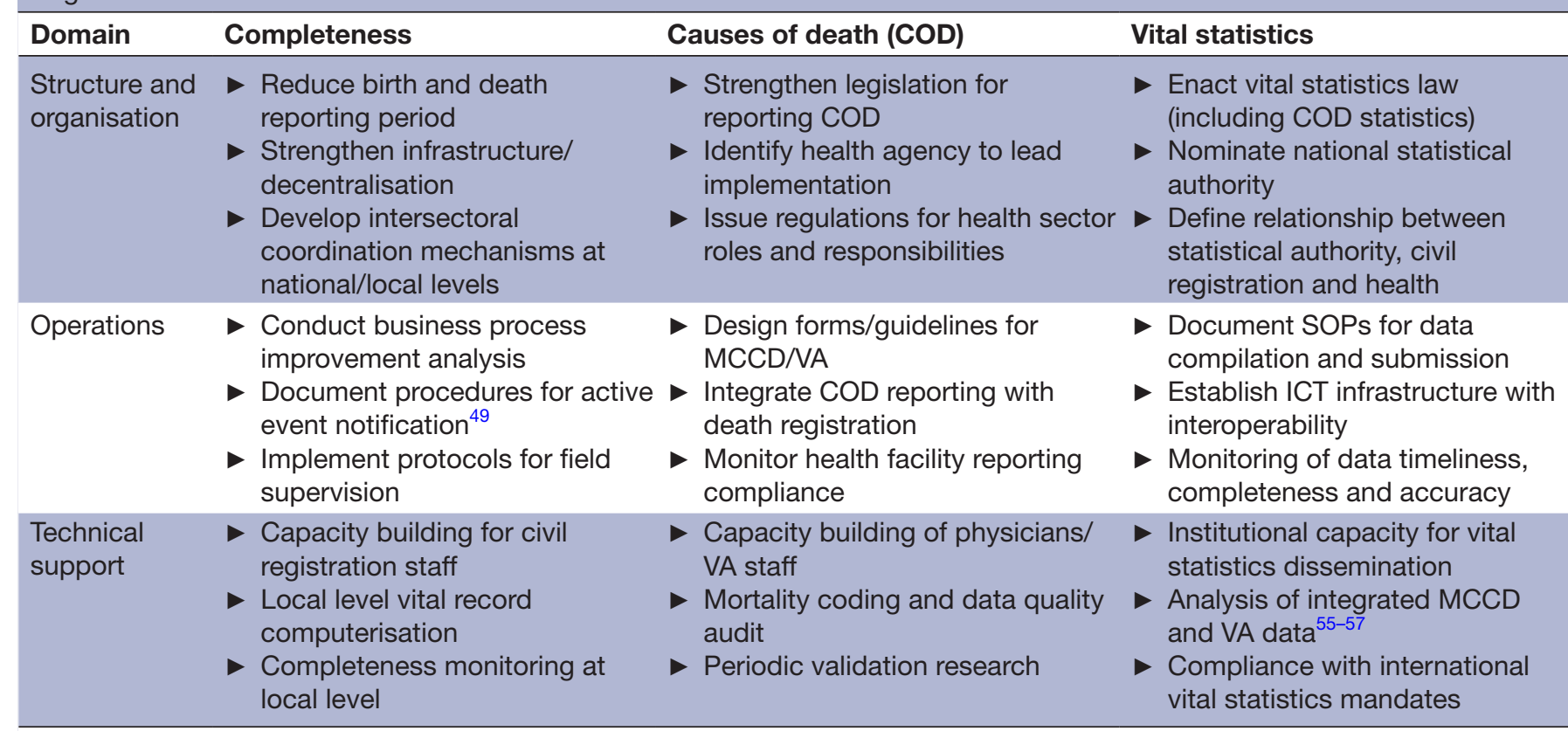

ICT, Information and Communication Technology; MCCD, Medical Certification of Cause of Death; SOP, Standard Operating Procedures; UNESCAP, United Nations Economic and Social Commission for Asia Pacific; VA, verbal autopsy.

and interim needs for reliable mortality statistics by age, sex and cause. It is self-evident that for all SEAR countries, except Bhutan, Maldives and Timor Leste, the large populations will necessarily require a long lead time to achieve high levels of national data quality, particularly in regard to data on causes of death through either MCCD or VA. This lead time could be up to a few years in medium sized countries (Sri Lanka, Thailand, DPR Korea and Nepal), but even up to 1-2 decades for the larger countries (India, Indonesia, Bangladesh and Myanmar). Therefore, the development plans for these countries would need to include a strategy to target selected locations with technical support for strengthening cause of death attribution as well as for data processing and analysis, to enable the generation of interim population referenced mortality statistics for monitoring, evaluation and policy action.

Depending on national population size and existing status of system design and performance, these defined populations could be in the form of sentinel clusters, nationally representative samples of districts or specific urban/rural locations with currently better system performance. In all instances, the selected clusters should meet defined criteria on population sample size for reliable mortality measurement. ${ }^{51}$ These sites could be the focus of implementation and operations research activities to design improved business processes, test tools and methods for causes of death, and measure interim population referenced mortality indicators. The strategic plan must clearly mention the protocols for periodic data quality assessment, particularly to monitor completeness of death registration and quality of causes of death from
MCCD and VA. ${ }^{52}$ The programme schedule must articulate specific interim time-bound targets and deliverables for production of mortality statistics in the selected populations preferably within 2-3 years of commencement of the system development programme, which will demonstrate success in implementation. Once a 'proof of concept' is established, the lessons learnt from such strategies would be the foundation for incremental scale up over the next decade, to increase national coverage of these system strengthening interventions. ${ }^{3}$

At the regional level, there are several common areas in which coordination and support could be provided to SEAR countries, particularly around strengthening attribution of cause of death as well as in production of useable statistics. Such broader needs could be addressed through regional level stewardship for setting priorities for targets and goals, harnessing technical support from regional and global institutions, and for resource mobilisation. Regional and national academic institutions are also required to participate in capacity building strategies for personnel from different sectors and institutions with specified roles and responsibilities in data capture and processing, as an essential element to ensure sustainability. ${ }^{53}$

\section{CONCLUSIONS}

The onset of the COVID-19 pandemic has brought to the fore the urgent need for reliable mortality statistics for WHO SEAR countries. Available mortality estimates from statistical models are clearly inadequate for the purposes for which such data are required, whether to 
identify geographical areas and population subgroups that are most affected, or to understand the overall impact of the pandemic on population health. ${ }^{54}$ Reliable empirical mortality data are also required for quantifying disease burden from other infectious diseases, noncommunicable diseases and injuries. A realistic understanding of these shortcomings, along with knowledge of the current operational characteristics of mortality statistics programmes in SEAR countries, as presented in this article, is essential to plan improvements in data availability. Customised national strategic development plans that focus on system design, capacity building and mortality statistics production, sustained over the next 1-2 decades, are necessary to realise the immediate and long-term goals for mortality statistics in South East Asian countries.

\section{Twitter Chalapati Rao @ChalapatiRa013}

Contributors CR conceptualised the research, led the analysis and drafted the initial version. KB and MK contributed to the data compilation and analysis. VT critically reviewed the initial draft and made relevant modifications. All authors reviewed and contributed to the final version of the manuscript.

Funding The authors have not declared a specific grant for this research from any funding agency in the public, commercial or not-for-profit sectors.

Competing interests None declared.

Patient consent for publication Not applicable.

Provenance and peer review Not commissioned; externally peer reviewed.

Data availability statement Data are available in a public, open access repository.

Supplemental material This content has been supplied by the author(s). It has not been vetted by BMJ Publishing Group Limited (BMJ) and may not have been peer-reviewed. Any opinions or recommendations discussed are solely those of the author(s) and are not endorsed by BMJ. BMJ disclaims all liability and responsibility arising from any reliance placed on the content. Where the content includes any translated material, BMJ does not warrant the accuracy and reliability of the translations (including but not limited to local regulations, clinical guidelines, terminology, drug names and drug dosages), and is not responsible for any error and/or omissions arising from translation and adaptation or otherwise.

Open access This is an open access article distributed in accordance with the Creative Commons Attribution Non Commercial (CC BY-NC 4.0) license, which permits others to distribute, remix, adapt, build upon this work non-commercially, and license their derivative works on different terms, provided the original work is properly cited, appropriate credit is given, any changes made indicated, and the use is non-commercial. See: http://creativecommons.org/licenses/by-nc/4.0/.

\section{ORCID iDs}

Chalapati Rao http://orcid.org/0000-0002-9554-0581

Matthew Kelly http://orcid.org/0000-0001-7963-2139

\section{REFERENCES}

1 United Nations General Assembly. Transforming our world: the 2030 agenda for sustainable development. A/RES/70/1, 2015. Available: https://www.un.org/ga/search/view_doc.asp?symbol=A/RES/70/1\& Lang $=\mathrm{E}$

2 Mills SL, Abouzahr C, Kim JH. Civil registration and vital statistics (CRVS) for monitoring the sustainable development goals. Washington D.C: World Bank Group, 2017. http://documents. worldbank.org/curated/en/979321495190619598/Civil-registrationand-vital-statistics-CRVS-for-monitoring-the-Sustainabledevelopment-goals-SDGS

3 Rao C. Elements of a strategic approach for strengthening national mortality statistics programmes. BMJ Glob Health 2019;4:e001810.

4 World Health Organization. About who in the South East Asia region New Delhi, 2021. Available: https://www.who.int/southeastasia/ about
5 Rao C, Kelly M. Empiricism in non-communicable disease mortality measurement for the Asia-Pacific: lost in translation. BMJ Glob Health 2020;5:e003626.

6 Boerma T, Victora C, Abouzahr C. Monitoring country progress and achievements by making global predictions: is the tail wagging the dog? Lancet 2018;392:607-9.

7 AbouZahr C, Boerma T, Hogan D. Global estimates of country health indicators: useful, unnecessary, inevitable? Glob Health Action 2017;10:1290370.

8 Mathers CD. History of global burden of disease assessment at the world Health organization. Arch Public Health 2020;78:77.

9 Institute for Health Metrics and Evaluation. Global burden of disease (GBD), 2019. Available: http://www.healthdata.org/gbd/ 2019

10 Global Burden of Disease Study 2019 (GBD 2019). Data Resources [Internet]. Institute of Health Metrics and Evaluation, University of Washington, 2020. Available: http://ghdx.healthdata.org/gbd-2019

11 World Health Organization. WHO Methods and data sources for country level causes of death, 2000 - 2019. Global health estimates technical paper WHO/DDI/DNA/GHE/2020.2. Geneva: World Health Organization, 2020. https://www.who.int/data/global-healthestimates

12 The Global Health Observatory (GHO). Summary tables of mortality estimates by cause, age and sex, by country, 2000-2019. Geneva: World Health Organization, 2020. https://www.who.int/data/gho/ data/themes/mortality-and-global-health-estimates/ghe-leadingcauses-of-death

13 World Health Organization. World health statistics 2021: monitoring health for the SDGs. Geneva: WHO, 2021. https://www.who.int/data/ gho/publications/world-health-statistics

14 World Health Organization. Table 4.1: Characteristics of country vital registration data and (criteria for) inclusion/exclusion. WHO Methods and data sources for country level causes of death, 2000 - 2019. Global health estimates technical paper WHO/DDI/DNA/GHE/2020.2. Geneva: World Health Organization, 200. https://www.who.int/data/ global-health-estimates

15 Vos T, Lim SS, Abbafati C, et al. Global burden of 369 diseases and injuries in 204 countries and territories, 1990-2019: a systematic analysis for the global burden of disease study 2019. The Lancet 2020;396:1204-22.

16 United Nations Population Division. World population prospects 2019. New York: United Nations Department of Economic and Social Affairs, 2019. https://population.un.org/wpp/

17 World Health Organization. Global Health Estimates Geneva: WHO; 2019 [Available from. Available: https://www.who.int/healthinfo/ global_burden_disease/en/

18 Bulatao RA, Stephens PW. Global estimates and projections of mortality by cause, $1970-2015$. Document No:WPS 1007 Washington: World Bank, 1992. https://ideas.repec.org/p/wbk/ wbrwps/1007.html

19 Mathers CD, Fat DM, Inoue M, et al. Counting the dead and what they died from: an assessment of the global status of cause of death data. Bull World Health Organ 2005;83:171-7.

20 Rao C. Mortality estimates for South East Asia, and indepth mortality surveillance: necessary but not sufficient? Int J Epidemiol 2013;42:1196-9.

21 World Health Organization Regional Office for South East Asia. Regional consultation on mortality statistics. Report No.: SEAHSD-304. New Delhi: WHO-SEARO, 2007. http://www.searo.who. int/LinkFiles/Meetings_HSD-304.pdf

22 World Health Organization Regional Office for South East Asia. Regional strategy for strengthening the role of the health sector for improving CRVS (2015-2024). New Delhi: WHO SEARO, 2015. http://www.searo.who.int/entity/health_situation_trends/regional strategy_for_strengthening_the_role_of_the_health_sector_for_ improving_crvs.pdf?ua $=1$

23 United Nations Economic and Social Commission for Asia and the Pacific. Regional action framework on civil registration and vital statistics in Asia and the Pacific. Bangkok; contract no, 2014. Available: https://getinthepicture.org/resource/regionalaction-framework-civil-registration-and-vital-statistics-asia-andpacific[Accessed 12.10.21].

24 United Nations Economic Commission for Asia and Pacific (UNESCAP). Getting everyone in the picture: a snapshot of progress midway through the Asian and Pacific civil registration and vital statistics decade 2015-2024, 2021. Available: https://getinthepicture. org/midterm-report

25 Vital Statistics Division Office of the Registrar General of India. Vital statistics of India based on the civil registration system, 2019. New Delhi: Ministry of Home Affairs, Government of India, 2021. https:// censusindia.gov.in/2011-Common/Annual_Report.html 
26 Rao C, Kelly M. A review of civil registration and vital statistics systems in 8 who SEAR countries: technical report commissioned by who SEARO. New Delhi: WHO Regional Office for South East Asia, 2020.

27 Mrkic S, Cobos MI, eds. Evaluation of the quality of civil registration and vital statistics systems. Handbook on civil registration and vital statistics systems: management, operation and maintenance revision 1. New York: Department of Economic and Social Affairs: United Nations Statistics Division, 2018. https://unstats.un.org/unsd/ demographic-social/Standards-and-Methods/files/Handbooks/crvs/ crvs-mgt-E.pdf

28 Tin Oung M, Richter K, Prasartkul P, et al. Myanmar mortality registration: an assessment for system improvement. Popul Health Metr 2017;15:34.

29 Office of the Registrar General of India. Extending the scheme for medical certification of causes of death to all medical institutions. Contract No.: S. No. 1/1/2014 - VS(MCCD)/3143-3210. New Delhi: Ministry of Home Affairs, Government of India, 2014. http:// censusindia.gov.in/2011-Documents/mccd_Report1/Circular2.pdf

30 Office of the Registrar General of India. Monitoring vital rates: action to be taken. Contract No.: Circular No. 2/6/2017 - VS (CRS. New Delhi: Ministry of Home Affairs, Government of India, 2017. http:// crsorgi.gov.in/web/uploads/download/CRS_Circular_Monthly.pdf

31 Government of Indonesia. Peraturan presiden (PERPRES) Nomor 62 Tahun 2019: strategi nasional percepatan administrasi kependudukan untuk pengembangan statistik hayati. [National strategy for the acceleration of population administration for the development of vital statistics], 2019. Available: https://peraturan. bpk.go.id/Home/Details/121658/perpres-no-62-tahun-2019

32 World Health Organization. Mortality: guidelines for certification and rules for coding. International Statistical classification of diseases and health related problems - tenth revision (ICD-10) volume 2: instruction manual 2. Geneva: World Health Organization, 1993: 30-65.

33 United Nations Statistics Division. Demographic and social statistics: demographic Yearbook system. New York: United Nations Department of Economic and Social Affairs, 2021. https://unstats. un.org/unsd/demographic-social/products/dyb/

34 Ministry of Public Health. Public health statistics 2561 (AD 2018). ISSN: 0857 3093. Bangkok, Thailand: Ministry of Public Health, 2020.

35 Vital Statistics Division Office of the Registrar General of India. Report on medical certification of cause of death, 2019. New Delhi: Ministry of Home Affairs, Government of India, 2021. https:// censusindia.gov.in/2011-Common/mccd.htm

36 Central Statistical Organization. Myanmar statistical Yearbook 2019. Myanmar: Ministry of Planning and Finance. Nay Pyi Taw, 2019. https://www.csostat.gov.mm/PublicationAndRelease/ StatisticalYearbook

37 Usman SK. Maldives health profile 2019. Ministry of health, male, 2021. Available: https://www.researchgate.net/publication/ 349367866_Maldives_Health_Profile_2019

38 Department of Census and Statistics: Sri Lanka. Vital statistics. Battaramulla, Sri Lanka, 2021. Available: http://www.statistics.gov.lk/ Population/Staticallnformation/VitalStatistics

39 Bhattarai S, Aryal A, Pyakurel M, et al. Cardiovascular disease trends in Nepal - An analysis of global burden of disease data 2017. Int J Cardiol Heart Vasc 2020;30:100602.

40 India State-Level Disease Burden Initiative Air Pollution Collaborators. Health and economic impact of air pollution in the states of India: the global burden of disease study 2019. Lancet Planet Health 2021;5:e25-38.

41 Rao C, Gupta A, Gupta M, et al. Premature adult mortality in India: what is the size of the matter? BMJ Glob Health 2021;6:e004451.

42 Mboi N, Murty Surbakti I, Trihandini I, et al. On the road to universal health care in Indonesia, 1990-2016: a systematic analysis for the global burden of disease study 2016. Lancet 2018;392:581-91.

43 Nichols EK, Byass P, Chandramohan D, et al. The who 2016 verbal autopsy instrument: an international standard suitable for automated analysis by InterVA, InSilicoVA, and tariff 2.0. PLoS Med 2018;15:e1002486.

44 Rao C, Mswia R, Bratschi M, et al. Estimating completeness of birth and death registration: methods and options for estimating completeness of civil registration. vital strategies. New York, 2020. Available: https://www.vitalstrategies.org/resources/estimatingcompleteness-of-birth-and-death-registration/

45 Aung E, Rao C, Walker S. Teaching cause-of-death certification: lessons from international experience. Postgrad Med $\mathrm{J}$ 2010;86:143-52.

46 World Health Organization. Verbal autopsy standards: ascertaining and attributing causes of death: the 2016 who verbal autopsy instrument. Geneva: WHO, 2017. http://www.who.int/healthinfo/ statistics/verbalautopsystandards/en/

47 Bundhamcharoen K, Limwattananon S, Kusreesakul K, et al. Contributions of national and global health estimates to monitoring health-related sustainable development goals in Thailand. Glob Health Action 2017;10:1266175.

48 United Nations Economic and Social Commission for the Asia Pacific. Midterm Report: Getting everyone in the picture: a snapshot of progress midway through the Asian and Pacific civil registration and vital statistics decade (2015 - 2024). Bangkok: UNESCAP, 2021. https://getinthepicture.org/midterm-report

49 Uddin M, Ashrafi SAA, Azad AK, et al. Improving coverage of civil registration and vital statistics, Bangladesh. Bull World Health Organ 2019;97:637-41.

50 Kelly M, Mathenge G, Rao C. Lessons learnt and pathways forward for national civil registration and vital statistics systems after the COVID-19 pandemic. J Epidemiol Glob Health 2021;11:262-5.

51 Begg S, Rao C, Lopez AD. Design options for sample-based mortality surveillance. Int J Epidemiol 2005;34:1080-7.

52 Rao C, Lopez AD, Yang G, et al. Evaluating national cause-of-death statistics: principles and application to the case of China. Bull World Health Organ 2005;83:618-25.

53 Rao C, Usman Y, Kelly M, et al. Building capacity for mortality statistics programs: perspectives from the Indonesian experience. $J$ Epidemiol Glob Health 2019;9:98-102.

54 Rao C. Medical certification of cause of death for COVID-19. Bull World Health Organ 2020;98:298-A

55 Porapakkham Y, Rao C, Pattaraarchachai J, et al. Estimated causes of death in Thailand, 2005: implications for health policy. Popul Health Metr 2010;8:14.

56 Adair T, Firth S, Phyo TPP, et al. Monitoring progress with national and subnational health goals by integrating verbal autopsy and medically certified cause of death data. BMJ Glob Health 2021;6.

57 Omar A, Ganapathy SS, Anuar MFM, et al. Cause-Specific mortality estimates for Malaysia in 2013: results from a national sample verification study using medical record review and verbal autopsy. BMC Public Health 2019;19:110. 